\title{
Application of Jaya Algorithm in finding Optimal placement and Sizing of Distributed Generation Units
}

\author{
Ankush Roy ${ }^{1}$, Dr.D.Rama Prabha ${ }^{2 *}$, \\ ${ }^{1}$ Schoolof Electrical Engineering,VIT,Vellore,India, ankush.roy03@gmail..com \\ $2^{2 *}$ Associate Professor,School of Electrical Engineering,VIT,Vellore,India,dramaprabha@ vit.ac.in \\ *Corresponding author,Email :dramaprabha@ vit.ac.in
}

\begin{abstract}
It is observed that the demands of electrical energy, distributed generation (DGs) units have become more emphatic in distribution systems. Recent years have witnessed the integration of distributed generation units has risen significantly. Proper placement of multiple generation units is required for reducing the power loss. In this paper the proposed technique consists of total power loss reduction, low investment costs and voltage stability improvement. Identification of optimal placement of DG units is achieved by the LSF for aforementioned technique. The proposed technique is analyzed using IEEE-69 radial system. The outcome verifies that the proposed technique is efficient, robust and effective.
\end{abstract}

Key Words: Distributed Generation Units, Jaya Algorithm, Optimal, Teaching Learning Based Optimization, Radial Distribution Networks.

\section{ABBREVIATIONS}

DG, Distributed Generation; LSF, Loss Sensitivity Factor; RDN, Radial Distribution Network; LFA, Load Flow Analysis; GA, Genetic Algorithm; SA, Simulated Annealing; OPF, Optimal Power Flow; PSO, Particle Swamp Optimization; BFOA, Bacterial Foraging Optimization Algorithm; BSOA, Backward Search Optimization Algorithm; DNO, Distribution Network Operators;DFS, Depth First Search.

\section{INTRODUCTION}

Technological progress, restructuring of power systems, feeders and transmission lines with hundreds of complex constraints have led to the rise in distributed generation as an alternating supply of electric power. The capacity range of DG unit lies below 20MW located close to the point of use [1]. From generation of entire power supply to standby or emergency operations or to use as a green power source, DG can be used anywhere. Small size of DG leads to low capital costs and less infrastructure. It reduces the pressure from distribution and transmission lines along with power reliability as backup or standby power [2-3].

Enhancement of distributed generation leads in increase in voltage profile, power quality and line losses reduction [4-7]. As a result, reduction in the demand of power required from the grid thereby reducing the need of feeders for network to grid connection. Application of DG unit in radial network to maximize the output in the network is discussed in [8].

Due to high $\mathrm{X} / \mathrm{R}$ ratio and complex structure in radial network the conventional LFA failed [9]. Many methods are applied for radial load flow analysis such as back forward sweep which applies Kirchhoff's KCL and KVL laws to find the bus voltages [10-11]. Another method efficient as much as back/forward sweep method is Jacobian matrix [12]. Object oriented paradigm method has been applied for solving radial distribution system [13].

A number of approaches such as the classical approach of placement of capacitor banks along the transmission lines is discussed in [14-15], using non-linear programming [16]. To reduce the distributed generation unit's cost of power the GA is used [17]. However, operational problems can be seen by proper placement of distributed generation [18].

By using PSO, in less simulation time, a near global optimal solution can be found out. However, unspecified power factor for the placement of DG units was done, which cannot be practically implemented for DG [19-20]. The primary purpose of DG units of fixed capacity in the network is to lessen the total power loss profile by using a combination of PSO and GA in [21-23].

With the help of LSF, buses are sorted in decreasing order and the best three locations are selected for installing DG units. Second, a novel optimization technique based on a Jaya algorithm [24] is used for the sizing of the DGs. 


\section{PROBLEM FORMULATION}

A proposed methodology aims at reducing the total power loss, improving the voltage stability and minimize the operational cost DG units. The objective function is

$$
\text { MinimizeF }=\min \left(\alpha_{1} \Delta P L_{D G}+\alpha_{2} \Delta V_{D}+\alpha_{3} \Delta O C\right)
$$

where

$\sum_{q=1}^{i} \alpha_{q}=1.0, \alpha_{q}=[0,1]$

This objective function has the below mentioned constraints subjected to itself.

Power balance constraint

$\sum_{k=2}^{n} P_{b G, k s} \sum_{k=2}^{n} P_{k}+\sum_{k=1}^{b} P_{\text {Loss } k, k+1}$

Temperature limits

$\left|J_{h i k+1}\right| \leq\left|J_{h i k+1, \max }\right|$

Voltage drop limits

$\left|V_{1}-V_{k}\right| \leq \Delta V_{\max }$

Distributed generation capacity limits

$P_{D G T}^{\min } \leq P_{D G T} \leq P_{D G T}^{\max }$

where $P_{D G \mathrm{~min}}^{\min }=0.1 \sum_{k=2} P_{k}$ and

$$
P_{\text {DGT }}=0.6 \sum_{k=2}^{n} P_{k i}
$$

The infraction of these inequality constraints affects the objective function.

\subsection{Reduction of Power Loss}

The power loss index is the ratio of the power loss with DG to the total power loss and represented as

$$
\Delta P L_{D G}=\frac{P_{D G \text { Thas }}}{P_{\text {Tloss }}}
$$

Minimizing the power loss index increases the net power loss reduction

\subsection{Voltage Deviation Index}

$$
\Delta V_{D}=\max \left(\frac{V_{1}-V_{k}}{V_{1}}\right) \forall k=1,2 \ldots, n
$$

The voltage deviation index will be minimized to zero by installing DG.

\subsection{Minimization of Operational Cost}

The total operating cost is given by the formula

$T O=\left(c_{1} P_{D G \text { Tlass }}\right)+\left(c_{2} P_{D G T}\right)$

Net operating cost that to be reduced is given by

$$
\triangle O C=\frac{T O C}{C_{2} P_{D G T}^{\max }}
$$

\subsection{Model of Load}

The expression for bus voltage magnitude, real power and reactive power is called a load model and is given as

$$
\begin{aligned}
& P_{k}=\rho P_{k \text { actual }} V_{k}^{a} \\
& Q_{k}=\rho Q_{k \text { actul }} V_{k}^{\theta}
\end{aligned}
$$

$\alpha, \beta$ are termed as the load model coefficients. Table 1 contains the magnitudes of $\alpha, \beta$ with respect to each load type.

Table 1: Different types of load and their $\alpha, \beta$ values

\begin{tabular}{|l|c|c|}
\hline \multicolumn{1}{|c|}{ Load Type } & $\alpha$ & $\beta$ \\
\hline $\begin{array}{l}\text { Constant power (CP) } \\
{[21]}\end{array}$ & 0 & 0 \\
\hline $\begin{array}{l}\text { Constant curment } \\
\text { (CC) [21] }\end{array}$ & 1 & 1 \\
\hline $\begin{array}{l}\text { Constant impedance } \\
\text { (CI) [21] }\end{array}$ & 2 & 2 \\
\hline $\begin{array}{l}\text { Residential load } \\
\text { RES) [21] }\end{array}$ & 0.92 & 4.04 \\
\hline $\begin{array}{l}\text { Industrial load (IND) } \\
{[21]}\end{array}$ & 0.18 & 6 \\
\hline $\begin{array}{l}\text { Commercial load } \\
\text { (COM) [21] }\end{array}$ & 1.51 & 3.4 \\
\hline
\end{tabular}

\subsection{Loss Sensitivity Factor}

LSF is utilized to minimize the solution space for the optimal location of DG. Loss sensitivity factor is given by 


$$
L S F(k, k+1)=\frac{\partial P_{\text {Linelore }}}{\partial P_{k+1 \text { eff }}}==\frac{2 P_{k+1, g f f^{\prime}} R_{k, k+1}}{\|\left. V_{k+1}\right|^{2}}
$$

The sensitivity for each bus is calculated and they are ranked in the descending order. The top ranked buses are selected for the location of DGs.

\section{OVERVIEW OF JAYA ALGORITHM}

Algorithmic specific parameter increases the overall computational time because of the improper tuning of such parameters and as a result accurate results are not obtained. Professor constructed a new algorithm to overcome these above- mentioned shortcomings by negating the usage of any algorithmic specific parameters. In 2011 he came up with an algorithm called Teaching-learning based algorithm. The TLBO algorithm gained wide popularity amongst various researchers since 2015.[24]

Keeping in mind the huge success of this algorithm Prof. Rao proposed another almost identical, yet simpler algorithm called the Jaya algorithm. The main difference is the two phases in TLBO (teaching phase and learning phase) this algorithm is composed of only one phase and it is significantly easier to program and apply. Also, Jaya algorithm works much differently than TLBO algorithm. [24]

\subsection{Framework of Jaya Algorithm} shown as

$f(x)$ is the function to be minimized. The equation is

$X_{j, k, i}^{\prime}=X_{j, k, i}+r l, j, i\left(X_{j, b e s t, I}-\left|X_{j, k, i}\right|\right)-r 2, j, i\left(X_{j, w o r s t}, I\right.$

- $|X j, k, i|) \quad E q .(13)$

$X^{\prime} j, k, i$ is the updated value of $X_{j, k, i}$ and two random numbers are assumed $r l, j, i$ and $r 2, j, i$ within range $[0,1]$ for the $j^{\text {th }}$ variable during the $i^{\text {th }}$ iteration. The term " $r l, j, i$ ( ( $X_{j}$, best,$i^{-}$ $|X j, k, i|)$ " depicts "the proclivity of the solution travelling towards the best possible solution" and the term "- $r 2, j, i$ $\left(X_{j}\right.$,worst,$\left.i^{-}|X j, k, i|\right)$ )" depicts "the proclivity of the solution travelling away from the worst possible solution" [24].

\subsection{Application of Jaya Algorithm to find DG Sizing}

Step 1: Data comprising of the respective buses is inputted.

Step 2: Load flow analysis is done.
Step 3: Identification of the appropriate location for the installation of the respective DGs using the LSF. The LSF for (12) bus is calculated (from the power flow) by using the equation mentioned in the problem formulation.

Step 4: The implementation of the JAYA algorithm on the initial sample of data gathered to find most favorable sizing of the DGs with the following parameters mentioned below:

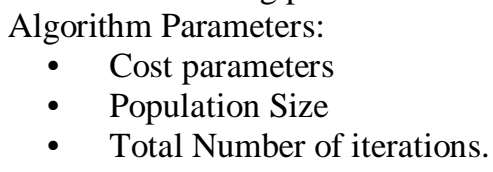

Step 5: Applying equation (6) mentioned above to obtain the best solution for a finite number of iterations (In this case 50 such runs).

Step 6: Repeat Step 1-Step 5 for all the different bus data for the different load types.

\section{SIMULATION AND RESULTS}

The algorithm was carried out on IEEE-69 radial system. The weighing parameters are chosen based on the priority given to each of the objective constraints which are voltage deviation, power loss minimization and minimization. The value of the weighing parameters are $\alpha_{1}=0.5, \alpha_{2}=0.4, \alpha_{3}=0.1, C_{1}=4$ $\$ / \mathrm{kW}$ and $C_{2}=5 \$ / \mathrm{kW}$. The value of $C_{2}$ has been chosen as slightly greater than $C_{1}$ because the maintenance and installation costs of DG have also been taken into consideration. The efficiency of the proposed algorithm has been measured by testing it on systems with different load types.Also, two different power factors (1 and 0.866) are considered at which the DG operates for the testing. The software used for this experiment is MATLAB.

\subsection{Algorithm applied on IEEE 69 bus system}

The system used for an experiment has a total of 69 buses with 68 branches. The total $\mathrm{P}$ is 3.80 mega-watts and the total $\mathrm{Q}$ is 2.69 mega volt amps (reactive) respectively. 
Table 2: The analysis of the performance for $\mathrm{CC}$ and $\mathrm{CP}$ load models

\begin{tabular}{|c|c|c|c|c|c|c|c|c|}
\hline & \multicolumn{6}{|c|}{ Constant Power } & \multirow{2}{*}{\multicolumn{2}{|c|}{ Constant Current }} \\
\hline & \multicolumn{2}{|c|}{$\begin{array}{l}\text { Constant Power } \\
\text { ( Light ) }\end{array}$} & \multicolumn{2}{|c|}{$\begin{array}{l}\text { Constant Power } \\
\text { ( Full ) }\end{array}$} & \multicolumn{2}{|c|}{$\begin{array}{l}\text { Constant Power } \\
\text { ( Heavy ) }\end{array}$} & & \\
\hline & $\begin{array}{l}\text { No } \\
\text { DG }\end{array}$ & DG & $\begin{array}{l}\text { No } \\
\text { DG }\end{array}$ & DG & $\begin{array}{l}\text { No } \\
\text { DG }\end{array}$ & DG & $\begin{array}{l}\text { No } \\
\text { DG }\end{array}$ & DG \\
\hline $\begin{array}{l}\text { DG Size } \\
\text { (MW) } \\
\text { (Bus no.) }\end{array}$ & & $\begin{array}{l}0.1991(17) \\
0.64593(60) \\
0.24532(63)\end{array}$ & & $\begin{array}{l}0.3061(17) \\
1.3388(60) \\
0.49763(63)\end{array}$ & & $\begin{array}{l}0.49964(17) \\
1.9939(60) \\
0.55593(63)\end{array}$ & & $\begin{array}{l}0.28651(27) \\
0.39841(65) \\
1.6325(61)\end{array}$ \\
\hline $\begin{array}{l}\text { Power loss } \\
(k W)\end{array}$ & 51.607 & 17.634 & 225 & 73.435 & 652.54 & 198.27 & 188.75 & 67.008 \\
\hline $\begin{array}{l}\% \text { loss } \\
\text { reduction }\end{array}$ & & 65.792 & & 67.363 & & 69.615 & & 64.499 \\
\hline$\Delta \mathrm{PL}_{\mathrm{DG}}$ & & 0.34208 & & 0.32657 & & 0.30389 & & 0.35501 \\
\hline $\mathbf{V}_{\text {worst }}(\mathbf{p . u})$ & $\begin{array}{l}0.9566 \\
(65)\end{array}$ & $\begin{array}{l}0.9999 \\
(61)\end{array}$ & $\begin{array}{l}0.95629 \\
(27)\end{array}$ & $\begin{array}{l}0.98069 \\
(27)\end{array}$ & $\begin{array}{l}0.8448 \\
(65)\end{array}$ & $\begin{array}{l}0.95565 \\
(65)\end{array}$ & $\begin{array}{l}0.91755 \\
(65)\end{array}$ & $\begin{array}{l}0.97418 \\
(27)\end{array}$ \\
\hline$\Delta \mathbf{V}_{\mathbf{D}}$ & 0.043321 & 0.0068492 & 0.043707 & 0.019315 & 0.15552 & 0.027201 & 0.08264 & 0.0149 \\
\hline TOC (\$) & & 3.2714 & & 6.4312 & & 9.1525 & & 6.946 \\
\hline
\end{tabular}

Table 3: The analysis of Performance for CI, RES, COM and IND load model

\begin{tabular}{|c|c|c|c|c|c|c|c|c|}
\hline & \multicolumn{2}{|c|}{ Constant Impedance } & \multicolumn{2}{|c|}{ Residential } & \multicolumn{2}{|c|}{ Commercial } & \multicolumn{2}{|c|}{ Industrial } \\
\hline & $\begin{array}{l}\text { No } \\
\text { DG }\end{array}$ & DG & $\begin{array}{l}\text { No } \\
\text { DG }\end{array}$ & DG & $\begin{array}{l}\text { No } \\
\text { DG }\end{array}$ & DG & $\begin{array}{l}\text { No } \\
\text { DG }\end{array}$ & DG \\
\hline $\begin{array}{l}\text { DG Size (MW) } \\
\text { (Bus no.) }\end{array}$ & & $\begin{array}{l}0.3124(17) \\
1.2501(60) \\
0.2883(63)\end{array}$ & & $\begin{array}{l}0.3163(17) \\
1.2976(60) \\
0.2766(63)\end{array}$ & & $\begin{array}{l}0.3178(17) \\
1.2788(60) \\
0.2858(63)\end{array}$ & & $\begin{array}{l}0.3140(17 \\
) \\
1.2968(60 \\
) \\
0.2964(63 \\
)\end{array}$ \\
\hline Power loss $(\mathrm{kW})$ & 158.92 & 53.543 & 164.98 & 40.854 & 157.05 & 44.038 & 171.5 & 32.88 \\
\hline$\%$ loss reduction & & 66.308 & & 75.237 & & 71.959 & & 80.826 \\
\hline$\Delta P L_{D G}$ & & 0.33692 & & 0.24763 & & 0.28041 & & 0.19174 \\
\hline $\mathbf{V}_{\text {worst }}$ (p.u) & $\begin{array}{l}0.92469 \\
(65)\end{array}$ & $\begin{array}{l}0.98368 \\
(27)\end{array}$ & $\begin{array}{l}0.92172 \\
(65)\end{array}$ & $\begin{array}{l}0.98332 \\
(27)\end{array}$ & $\begin{array}{l}0.9242 \\
(65)\end{array}$ & $\begin{array}{l}0.98398 \\
(27)\end{array}$ & $\begin{array}{l}0.9196 \\
(65)\end{array}$ & $\begin{array}{l}0.98249 \\
(27)\end{array}$ \\
\hline$\Delta \mathbf{V}_{\mathbf{D}}$ & 0.0753 & 0.016325 & 0.07828 & 0.01668 & 0.07581 & 0.01601 & 0.08031 & 0.01751 \\
\hline TOC (\$) & & 5.5536 & & 5.6724 & & 5.6472 & & 5.7228 \\
\hline
\end{tabular}




\subsubsection{Results for the various types of loads}

LSF was selected for calculating the suitable location for the DG installation. The LSF of all the buses have been calculated in MATLAB and then arranged in decreasing fashion. It was observed that a considerable reduction in power loss was not caused by the fixing of more than three DGs so only three units were placed at the locations 17, 60 and 63. For the optimal size calculation of the DG, JAYA technique was used.

The results for various load observed that the per cent loss reduction is clearly above 64.49 per-cent (lowest for CC load) for all the type of loads proving the effectiveness of the proposed algorithm.
Also to be mentioned is the fact that the Total Cost has been significantly reduced for all the load types when JAYA technique was used of 9.1525\$). The reduction in power loss has been most significant in Industrial Load type with per cent of $80.826 \%$.Thus proving the algorithm to be immensely effective for Industrial Loads.

It is to be mentioned that JAYA Algorithm has been applied for 50 different runs and then the Average of these 50 samples have been taken to construct the abovementioned tables of data as we have used randomize function to get the initial inputs of the DG units.

\subsection{Algorithmic comparison for the system}

Table 4: Algorithm comparison with power factor $=1$.

\begin{tabular}{|c|c|c|c|c|c|c|c|c|}
\hline METHOD & $\mathrm{P}_{\text {DGTloss }}(\mathrm{kW})$ & $\begin{array}{l}\text { Percentage } \\
\text { Loss } \\
\text { reduction }\end{array}$ & $\begin{array}{l}V_{\text {worat }}(\mathrm{p} . \mathrm{u})(\mathrm{bu} \\
\text { s) }\end{array}$ & $\begin{array}{l}\text { Location } \\
\text { of DG }\end{array}$ & $\begin{array}{l}\text { Size of } \\
\text { DG(MW) }\end{array}$ & $\mathrm{P}_{D G I}(\mathrm{MVA})$ & p.f. & $\begin{array}{l}\text { TOC } \\
\text { (\$) }\end{array}$ \\
\hline GA [19] & 89.0 & 60.44 & $0.9936(57)$ & $\begin{array}{l}21 \\
62 \\
64\end{array}$ & $\begin{array}{l}0.9299 \\
1.0751 \\
0.9924\end{array}$ & 2.9974 & Unity & 15343.0 \\
\hline PSO [19] & 83.3 & 63.02 & $0.9901(65)$ & $\begin{array}{l}61 \\
63 \\
17\end{array}$ & $\begin{array}{l}1.1998 \\
0.7958 \\
0.9923\end{array}$ & 2.9879 & Unity & 15272.3 \\
\hline GA/PSO [19] & 81.2 & 63.95 & $0.9925(65)$ & $\begin{array}{l}63 \\
61 \\
21\end{array}$ & $\begin{array}{l}0.8848 \\
1.1926 \\
0.9106\end{array}$ & 2.9880 & Unity & 15264.4 \\
\hline SA [12] & 77.2 & 65.73 & $0.9811(61)$ & $\begin{array}{l}18 \\
60 \\
65\end{array}$ & $\begin{array}{l}0.4203 \\
1.3311 \\
0.4299\end{array}$ & 2.1813 & Unity & 11214.9 \\
\hline BFOA [20] & 75.22 & 66.56 & $0.9808(61)$ & $\begin{array}{l}27 \\
65 \\
61\end{array}$ & $\begin{array}{l}0.2955 \\
0.4477 \\
1.3450\end{array}$ & 2.0882 & Unity & 10741.4 \\
\hline IWO[9] & 74.59 & 66.78 & $0.9802(18)$ & $\begin{array}{l}27 \\
65 \\
61\end{array}$ & $\begin{array}{l}0.2382 \\
0.4333 \\
1.3267 \\
\end{array}$ & 1.9983 & Unity & 10288.86 \\
\hline JAYA & 73.362 & 67.395 & $0.98022(27)$ & $\begin{array}{l}17 \\
60 \\
63 \\
\end{array}$ & $\begin{array}{l}0.30669 \\
1.332 \\
0.44621 \\
\end{array}$ & 2.0849 & Unity & 10.4 \\
\hline
\end{tabular}


Ankush Roy et al., International Journal of Emerging Trends in Engineering Research, 8(10), October 2020,7625 - 7632

Table 5: Algorithm comparison with power factor $=0.86$

\begin{tabular}{|c|c|c|c|}
\hline METHOD & $\mathrm{P}_{\text {DGTlass }}(\mathrm{kW})$ & $\begin{array}{l}\text { Percentage } \\
\text { Loss } \\
\text { reduction }\end{array}$ & $V_{\text {worst }}(p . u)(b u s)$ \\
\hline SA[12] & 16.27 & 92.77 & $0.9886(61)$ \\
\hline $\begin{array}{l}\text { BFOA } \\
{[20]}\end{array}$ & 12.91 & 94.26 & $0.9897(64)$ \\
\hline IWO[9] & 13.64 & 93.92 & $0.9947(68)$ \\
\hline JAYA & 16.773 & 92.546 & $0.98253(27)$ \\
\hline
\end{tabular}

\subsubsection{Comparison of different algorithms}

Comparison of for the various types of algorithms has been tabulated in Table 4 and Table 5 along with power factor 1 and 0.866. It was observed that the Jaya technique an effective of the above - mentioned algorithms for the sizing of DG system in the appropriate locations of bus found out using LSF method. The value of DG Placement with the utilization of Jaya Algorithm is 2.0849 for unity pf and 2.1232 for pf = 0.866 . The percent loss reduction in case of the aforementioned algorithm is almost on the same bench mark as the other algorithms but more than the old heuristic optimization techniques. However, the main advantage of using Jaya algorithm over others is the significant reduction the Total Cost for the placement of DGs (minimum in both the cases). It should be also mentioned that the main advantage of using Jaya algorithm is the usage of a smaller number of constraints when compared with others.

\subsection{Comparison voltage profile and line losses with and without installation of DGs in IEEE-69 Bus system}

\subsubsection{Voltage Profile Comparison}

The following figure was obtained by applying the algorithm to the different types of loads.

The loads depicted in the $\mathrm{Y}$-axis are mentioned in the table below:

\begin{tabular}{|c|c|}
\hline Type of load & Load System \\
\hline 1 & Constant Power (Light) \\
\hline 2 & Constant Power (Heavy) \\
\hline 3 & Constant Power (Full) \\
\hline 4 & Constant Current \\
\hline 5 & Constant Impedance \\
\hline
\end{tabular}

\begin{tabular}{|l|l|l|l|l|}
\hline $\begin{array}{l}\text { Location } \\
\text { of DG }\end{array}$ & $\begin{array}{l}\text { Size of } \\
\text { DG } \\
\text { (MW) }\end{array}$ & P $_{\text {DGI }}$ (MVA) & p.f. & $\begin{array}{l}\text { TOC } \\
\text { (\$) }\end{array}$ \\
\hline 18 & 0.5499 & 2.3757 & 0.866 & 10352.0 \\
60 & 1.1954 & & & \\
65 & 0.3121 & & & \\
\hline 27 & 0.3782 & 2.3587 & 0.866 & 10265.1 \\
65 & 0.3283 & & & \\
61 & 1.3362 & & & \\
\hline 27 & 0.3709 & 2.0520 & 0.866 & 8939.56 \\
65 & 0.3157 & & & \\
61 & 1.0904 & & & \\
\hline 17 & 0.2962 & 2.1232 & 0.866 & 9.2736 \\
60 & 1.3584 & & & \\
63 & 0.46837 & & & \\
\hline
\end{tabular}

Comparison of Voltage Magnitude with and without DGs in IEEE-69 Bus system

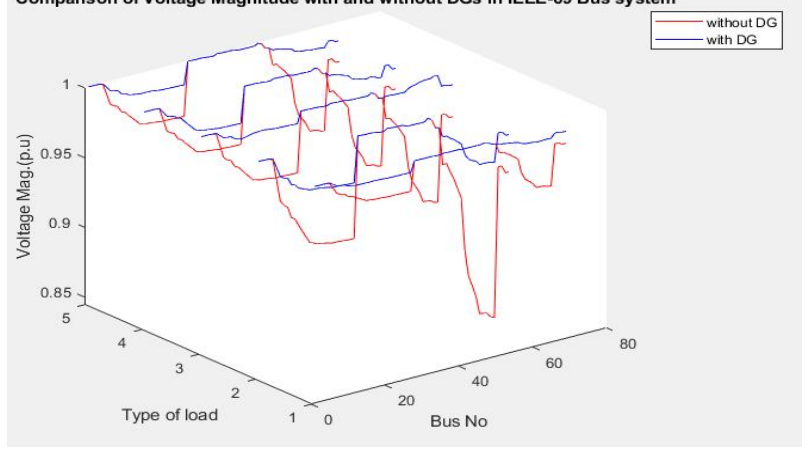

Figure 1 : Comparison of results

The above-mentioned graph shows the voltage magnitude comparison of the various load systems. The voltage magnitudes are projected in per unit analysis for better graphical display of the data. We observe that there was a increment in the enhancement of the voltage profiles while the placements of the DGs have taken place. This reveals the efficacy and the robustness of the Jaya algorithm. We can observe that in Constant Power Heavy Load systems there is a substantial amount of improvement in the voltage profile.

\subsubsection{Line loss comparison}

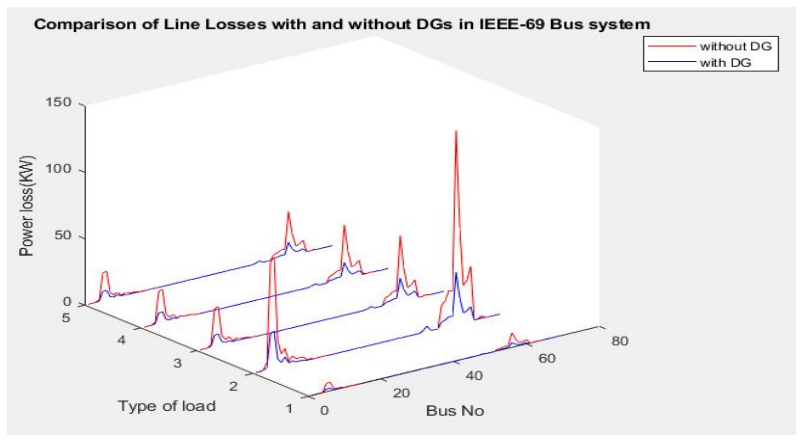

Figure 2 : Results of line losses in presence with and without DGs 
The above-mentioned figure shows the line losses comparison of the results (In this case CP, CI and CC Load). We observe that there was a significant reduction in the line losses when DG units have been placed in the optimum bus sites. This depicts the robustness of the proposed algorithm with the most effectiveness in Constant Power Heavy Load system and then equally in the rest of the load systems. Reduced power loss helps in the minimization of the main objective function which in turn enhances the total steadiness of the system and negates any unwanted power loss.

\section{CONCLUSION}

The paper presents a novel proposed optimization method termed as Jaya Algorithm. This study was to showcase the robustness of the algorithm and its applications in power system engineering. The algorithm has been used to cut down the line losses and the enhancement in the system. Upon simulation and calculations of various parameters like Vworst, $\triangle \mathrm{PLDG}$ and loss reduction percentage using Jaya algorithm and then upon comparison with different heuristic and metaheuristic algorithms it is found that Jaya algorithm proves to be more effective than the other algorithms. However Bacterial Foraging optimization technique has also proven to be quite feasible for the required purpose but when total cost factor is taken into consideration Jaya algorithm proves to be the most feasible method amongst all the others.

\section{ACKNOWLEDGEMENT}

The authors are thankful to VIT University, Vellore for providing them with impeccable infrastructural support as well as the motivation and encouragement to carry out this research and make this possible.

\section{REFERENCES}

1. T. Ackermann, Andersson G., et al., Distributed generation: a definition, Electric Power Systems Research 57 (2001) 195-204.

2. G. Pepermans, J Driesen, Belmans R, et al., Distributed generation: definition, benefits and issues, Energy Policy 33 (2005) 787-798.

3. El-Khattam W, Salama MMA. Distributed generation technologies definitions and benefits. Electric Power System Res 2004; 71:119-28.

4. Greatbanks JA, Begovic M, Pregelj A, Popovic DH Green TC. On optimization for security and reliability of power systems with distributed generation. In: Proc. IEEE bologna power tech., Bologna, Italy, June 2003.

5. P.P. Barker, R.W. de Mello, Determining the impact of distributed generation on power systems. Part1. Radial distribution systems, in: IEEE PES Summer Meeting, vol. 3, 2000, pp. 1645-1656.

6. An D. T. Le, M. A. Kashem, M. Negnevitsky, G. Ledwich, "Optimal Distributed Generation Parameters for Reducing Losses with Economic Consideration," IEEE Power Engineering Society General Meeting, pp.1-8, June 2007.

7. M. E. Baran and F. F. Wu, "Network reconfiguration in distribution systems for loss reduction and load balancing," IEEE Trans. Power Del., vol. 4, no. 2, pp. 1401-1407, Apr. 1989.

8. A. D. T le, M. A. Kashem, M. Negnevitsky, G. Ledwich, "Maximising Voltage Support in Distribution Systems by Distributed Generation," IEEE TENCON Conf., pp. 16, 2005.

9. Prabha, D.R. and Jayabarathi, T., 2016. Optimal placement and sizing of multiple distributed generating units in distribution networks by invasive weed optimization algorithm. Ain Shams Engineering Journal, 7(2), pp.683694.

10. A. Gomez Esposito and E. Romero Ramos, "Reliable load flow technique for radial distribution networks," in IEEE Transactions on Power Systems, vol. 14, no. 3, pp. 1063-1069, Aug 1999.

11. G. W. Chang, S. Y. Chu and H. L. Wang, "An Improved Backward/Forward Sweep Load Flow Algorithm for Radial Distribution Systems," in IEEE Transactions on Power Systems, vol. 22, no. 2, pp. 882-884, May 2007.

12. Fan Zhang and C. S. Cheng, "A modified Newton method for radial distribution system power flow analysis," in IEEE Transactions on Power Systems, vol. 12, no. 1, pp. 389-397, Feb 1997.

13. A. Losi and M. Russo, "Dispersed generation modeling for object-oriented distribution load flow," in IEEE Transactions on Power Delivery, vol. 20, no. 2, pp. 15321540, April 2005.

14. J. J. Grainger and S. H. Lee, "Optimum size and location of shunt capacitors for reduction of losses on distribution feeders," IEEE Trans. Power App. Syst., vol. PAS-100, pp. 1105-1118, Mar. 1981.

15. Chang, "Reconfiguration and capacitor placement for loss reduction of distribution systems," IEEE transaction on power systems, vol.23, no.4, Nov. 2008

16. Augugliaro A, Dusonchet L, Mangione S. Optimal capacitive compensation on radial distribution system 
using nonlinear programming. Electric Power System Res 1990;19:129-35.

17. M. Mardaneh, G. B. Gharehpetian, "Siting and Sizing of DG Units using GA and OPF Based Technique," IEEE Region 10 TENCON 2004 Conf., vol. 3, pp. 331-334, 21-24 Nov., 2004.

18. Mithulananthan, T. Oo, L. Van Phu, Distributed generator placement in power distribution system using genetic algorithm to reduce losses, Thammasat Int. J. Sci. Technol. 9 (July-September (3)) (2004).

19. El-Zonkoly, A.M.: “Optimal placement of multidistributed generation units including different load models using particle swarm optimization", IET Gener., Transm. Distrib., 2011, 5, (7), pp. 760-771

20. Lalitha, M. Padma, VC Veera Reddy, and V. Usha. "Optimal DG placement for minimum real power loss in radial distribution systems using PSO." Journal of Theoretical and Applied Information Technology 13.2 (2010): 107-116.

21. R.K. Singh, S.K. Gowsami, Optimum allocation of distributed generations based on nodal pricing for profit, loss reduction and voltage rise issue, Electrical Power Energy System32(2010)637-644.

22. M.H. Moradi, M. Abedini, A combination of genetic and particle swarm optimization for optimal DG location and sizing in distribution system, Electr.PowerEnergySyst.34(2012)66-74.

23. M. Ettehadi, H. Ghasemi, S. Vaez-Zadeh, Voltage stability based DG placement in distribution networks, IEEE Trans. PowerDeliv.28(1)(2013)171-178.

24. Rao, R. Jaya: A simple and new optimization algorithm for solving constrained and unconstrained optimization problems. International Journal of Industrial Engineering Computations , 7(1), 19-34. 
Ankush Roy et al., International Journal of Emerging Trends in Engineering Research, 8(10), October 2020, 7625 - 7632 